\title{
Qualidade textural de tomates cultivados em substratos orgânicos submetidos à aplicação de substâncias húmicas
}

\author{
Caroline Roberta Freitas Pires ${ }^{(1)}$, Luiz Carlos de Oliveira Lima(1), Eduardo Valério de Barros Vilas Boas ${ }^{(1)}$ \\ e Rosiana Rodrigues Alves ${ }^{(2)}$
}

(1)Universidade Federal de Lavras (Ufla), Departamento de Ciências dos Alimentos, Caixa Postal 37, CEP $37200-000$ Lavras, MG. E-mail: karolstrela@yahoo.com.br, Icolima@ufla.br, evbvboas@ufla.br (2)Ufla, Departamento de Ciências Exatas. Email: rosiagro@yahoo.com.br

\begin{abstract}
Resumo - O objetivo deste trabalho foi avaliar os efeitos de substâncias húmicas e de diferentes substratos orgânicos na qualidade textural dos frutos do tomateiro híbrido Vênus, em ambiente protegido. Utilizaram-se, quatro tipos de substratos: fibra de coco; fibra de coco e casca de café carbonizada $1 / 3$ (v/v); fibra de coco e casca de café carbonizada $2 / 3(\mathrm{v} / \mathrm{v})$; e casca de café carbonizada. As doses de substâncias húmicas (ácido húmico, $10 \%$ + ácido fúlvico 10,2\%) utilizadas foram $0,20,40$ e $80 \mathrm{~L} \mathrm{ha}^{-1}$, aplicadas ao substrato quinzenalmente, a partir do oitavo dia após o transplantio. O delineamento utilizado foi o de blocos ao acaso, em arranjo fatorial $4 \times 4$. Avaliaram-se firmeza dos frutos, percentagem de solubilização péctica e atividade enzimática (pectinametilesterase e poligalacturonase). Observou-se variação na atividade das enzimas pectinametilesterase e poligalacturonase, em consequência das doses de substâncias húmicas adicionadas, nos diferentes substratos. $\mathrm{O}$ efeito das doses de substâncias húmicas sobre a firmeza, solubilidade de pectinas e atividade enzimática, em frutos de tomate, depende do substrato utilizado. Frutos obtidos de plantas cultivadas em fibra de coco apresentaram aumento de firmeza e redução da percentagem de solubilização péctica com a aplicação de doses crescentes de substâncias húmicas.
\end{abstract}

Termos para indexação: Lycopersicon esculentum, substâncias húmicas, atividade enzimática, firmeza, solubilização péctica.

\section{Textural quality of tomatoes grown in organic substrates subjected to application of humic substances}

\begin{abstract}
The objective of this work was to evaluate the effects of humic substances and of different organic substrates on the textural quality of tomato fruit of the Vênus hybrid, in a protected environment. Four types of substrates were used: coconut fiber; coconut fiber and carbonized coffee husk 1/3 (v/v); coconut fiber and carbonized coffee husk $2 / 3(\mathrm{v} / \mathrm{v})$; and carbonized coffee husk. The humic substances (humic acid, $10 \%+$ fulvic acid, 10,2\%) dosages of 0, 20, 40 and $80 \mathrm{~L} \mathrm{ha}^{-1}$ were applied onto the substrates fortnightly from the eighth day after transplanting. The experimental design was in randomized block in a $4 \times 4$ factorial arrangement. Evaluations were done for fruit firmness, percentage of pectin solubilization, and enzymatic activity (pectinmethylesterase and polygalacturonase). Different enzymatic activities of pectinmethylesterase and polygalacturonase were observed according to the doses of humic substances added to the different substrates. The humic substances dosage effects of the humic substances in fruit firmness, pectin solubility and enzymatic activity were dependent upon the substrate used. Fruit grown in coconut fiber had an increase in firmness and a reduction in the percentage of pectin solubilization with the application of increasing doses of humic substances.
\end{abstract}

Index terms: Lycopersicon esculentum, humic substances, enzymatic activity, firmness, pectic solubilizing.

\section{Introdução}

A comercialização do tomate é constituída por diferentes atividades, que envolvem desde os cuidados que o produto requer ainda na planta, na fase pré-colheita, até sua apresentação ao consumidor. A etapa pré-colheita é muito importante, pois todo o processo de conservação, após a colheita, dependerá da qualidade que o produto adquiriu durante a fase de crescimento e desenvolvimento no campo (Kader et al., 1978).

A solução do solo contém quantidades variáveis de matéria orgânica dissolvida, composta principalmente por substâncias húmicas (Kalbitz et al., 2000). As substâncias húmicas são moléculas complexas, de elevado peso molecular, compostas por huminas, ácidos fúlvicos e ácidos húmicos (Guerra et al., 2008). 
São formadas por agregados moleculares heterogêneos, estabilizados por pontes de hidrogênio e interações hidrofóbicas (Piccolo, 2001), e podem favorecer o desenvolvimento do sistema radicular (Façanha et al., 2002; Zandonadi et al., 2007), o acúmulo de nutrientes (Vaughan et al., 1985), e a biossíntese de clorofilas (Ferrara \& Brunetti, 2008); podem, além disso, ter ação fito-hormonal e atuar nos processos fotossintéticos e no incremento da produtividade dos cultivos (Pizzeghello et al., 2001).

As substâncias húmicas, quando aplicadas à planta, podem levar ao aumento da atividade de enzimas como a fosforilase, fosfatase, citocromo oxidase, e à inibição de outras, como ácido indol acético (AIA) oxidase, fitase e peroxidase (Vaughan \& Ord, 1980).

Em culturas como a do arroz (Tejada \& Gonzalez, 2004), do trigo (Delfine et al., 2005) e da videira (Ferrara \& Brunetti, 2008), tem sido relatada a promoção de crescimento pela aplicação foliar de substâncias húmicas.

Há, no entanto, trabalhos que mostram que as substâncias húmicas podem ser prejudiciais à absorção de nutrientes pelas plantas, e que sugerem que as respostas às aplicações dessas substâncias podem depender de outros fatores, tais como sua composição e a espécie da planta (Delfine et al., 2005).

Estudos com tomate (Yildirim, 2007), uva (Ferrara \& Brunetti, 2008) e melão (Duenhas, 2004) avaliaram a ação das substâncias húmicas na qualidade de frutos, e deram destaque aos seus efeitos sobre atributos como sólidos solúveis totais, acidez titulável, $\mathrm{pH}$ e firmeza de frutos. A firmeza é um importante fator de qualidade em tomates para o consumo in natura, pois indica a tolerância do fruto ao transporte e ao manuseio, durante a colheita e a comercialização. Contudo, o mecanismo pelo qual os frutos têm sua firmeza reduzida não é completamente entendido. (Resende et al., 2004).

Muitos trabalhos têm se dedicado a elucidar os mecanismos responsáveis por mudanças na firmeza que ocorrem na pós-colheita dos frutos. É possível que estas alterações estejam associadas à perda de metil ésteres do homogalacturonano, em consequência da atividade da pectinametilesterase (PME), que remove os grupos metil éster dos resíduos do ácido alfa-D-galacturônico, das cadeias de polissacarídeos pécticos (Assis et al., 2004). De acordo com Ali (2004), a importância da PME no amaciamento dos frutos é ampliada, pois essa enzima contribui, direta ou indiretamente, para a ação de outras, ao criar um ambiente iônico adequado ou modificar a porosidade da parede celular, o que favoreceria o acesso de outras enzimas aos seus substratos potenciais. A desesterificação da cadeia de homogalacturonano a torna suscetível à atividade da poligalacturonase (PG) (Assis et al., 2004; Prasanna et al., 2007). Com o aumento da despolimerização mediada pela poligalacturonase, os poliuronídeos da parede celular aumentam a sua solubilidade em água, o que culmina com o amaciamento dos frutos. (Resende et al., 2004).

Em razão da escassez de trabalhos sobre as alterações na firmeza e na atividade enzimática em tomates, causadas pelo uso de substâncias húmicas associadas à utilização de substratos orgânicos, o presente trabalho teve como objetivo avaliar os efeitos de doses crescentes de substâncias húmicas (ácidos fúlvicos e húmicos) e dos substratos orgânicos fibra de coco e casca de café sobre a qualidade textural de frutos de tomateiro.

\section{Material e Métodos}

O experimento foi realizado no Setor de Olericultura, do Departamento de Agricultura da Universidade Federal de Lavras, de agosto de 2007 a janeiro de 2008. As sementes do híbrido Vênus, do grupo italiano, com hábito de crescimento determinado e frutos oblongos, foram semeadas em bandejas de poliestireno com 128 células, e irrigadas, diariamente, por microaspersão.

As mudas foram transplantadas para sacolas de plásticos, com capacidade de $7 \mathrm{~L}$, preenchidas com os substratos orgânicos, 35 dias após a semeadura. Os substratos foram constituídos por: fibra de coco, $\mathrm{S} 1$; fibra de coco e casca de café carbonizada $1 / 3(\mathrm{v} / \mathrm{v})$, S2; fibra de coco e casca de café carbonizada $2 / 3(\mathrm{v} / \mathrm{v})$, S3; e por casca de café carbonizada, S4.

As mudas foram distribuídas no espaçamento de $1,00 \mathrm{x} 0,80 \mathrm{x} 0,40 \mathrm{~m}$, que proporcionou o estande de 2,78 plantas $\mathrm{m}^{-2}$. O experimento foi conduzido em ambiente protegido, modelo capela, com $30 \mathrm{~m}$ de comprimento, $10 \mathrm{~m}$ de largura e $1,80 \mathrm{~m}$ de pé direito, coberto com polietileno de baixa densidade, com $150 \mu$ de espessura.

Foi realizada fertirrigação diária, de acordo com o estádio de desenvolvimento da cultura, conforme recomendação de Castellane \& Araújo (1994), com uso de gotejadores de múltiplas saídas (um por planta) 
e vazão média de $1 \mathrm{~L} \mathrm{~h}^{-1}$. O tempo de irrigação foi determinado após drenagem de $30 \%$ do volume total de água, e a frequência foi ajustada diariamente, de acordo com o estádio de desenvolvimento da cultura e as condições climáticas.

Como fonte de substâncias húmicas, foi utilizado o produto comercial Codahumus 20 (SAS, Almacelles, Espanha) - ácido fúlvico a 10,2\%, e ácido húmico a $10 \%$-, aplicados quinzenalmente, a partir do oitavo dia após o transplantio, nas dosagens $0,20,40$ e $80 \mathrm{~L} \mathrm{ha}^{-1}$, diretamente aos substratos.

Os frutos de terceiro e quarto cachos foram colhidos no estádio vermelho-alaranjado, para as análises da firmeza, hidrolases de parede celular (pectinametilesterase e poligalacturonase) e percentagem de solubilização péctica.

A firmeza da polpa foi determinada com o auxílio de um penetrômetro manual McCormik, modelo FT.011 (McCormick Fruit Treat Co., Yakima, Washington), com ponteira plana de diâmetro 7,94 mm, em dois pontos equidistantes, na porção equatorial de cada fruto, após a remoção de pequena porção da casca. Os resultados de firmeza foram expressos em Newtons. As pectinas total e solúvel foram extraídas segundo McCready \& McComb (1952) e determinadas colorimetricamente conforme Bittrer \& Muir (1962). A percentagem de solubilização foi determinada pela razão entre pectina solúvel e pectina total x 100 .

A pectinametilesterase foi determinada pela técnica descrita por Jen \& Robinson (1984). O substrato usado foi a pectina cítrica a $1 \%$, em $\mathrm{NaCl} 0,1 \mathrm{~mol} \mathrm{~L}^{-1}, \mathrm{pH}$ 7,0 , à temperatura ambiente. A taxa de desmetilação da pectina, adicionada do extrato enzimático, foi medida pela titulação da mistura da reação com $\mathrm{NaOH}$ $0,01 \mathrm{~mol} \mathrm{~L}^{-1}$, em $\mathrm{pH} 7$, por $10 \mathrm{~min}$. Uma unidade de atividade foi considerada como sendo a quantidade de enzima capaz de catalisar a desmetilação de pectina correspondente a 1,0 $\mu \mathrm{mol}$ de $\mathrm{NaOH} \mathrm{min}^{-1}$, nas condições do ensaio. Os resultados foram expressos em unidades de atividade por grama de enzima por minuto. Para a poligalacturonase, a extração foi realizada de acordo Buescher \& Furmanski (1978). Amostras de $5 \mathrm{~g}$ foram trituradas em politron com $50 \mathrm{~mL}$ de água destilada gelada a $4^{\circ} \mathrm{C}$. O homogenato resultante foi filtrado em papel. O resíduo foi lavado mais uma vez com água destilada e, em seguida, foi ressuspenso em $\mathrm{NaCl} 1 \mathrm{~mol} \mathrm{~L}^{-1}$ e submetido à homogeneização por 1 min. $\mathrm{O} \mathrm{pH}$ foi ajustado para $6, \mathrm{com} \mathrm{NaOH}$, e o novo homogenato foi incubado a $4^{\circ} \mathrm{C}$ por uma hora. Depois de incubado, o volume foi completado para $30 \mathrm{~mL}$, com $\mathrm{NaCl} 1 \mathrm{~mol} \mathrm{~L}^{-1}$, e filtrado com papel de filtro. O sobrenadante constituiu a fonte enzimática. A determinação da atividade enzimática foi realizada segundo Pressey \& Avants (1982). O extrato foi incubado com ácido galacturônico $0,25 \%$, em tampão acetato de sódio $37,5 \mathrm{~m} \mathrm{~mol} \mathrm{~L}^{-1}, \mathrm{pH} 5$, a $30^{\circ} \mathrm{C}$ por 3 horas. A reação foi interrompida em banho-maria fervente, e os grupos redutores liberados foram determinados pela técnica Somogyi modificada por Nelson (1944), com ácido galacturônico como padrão. Os resultados foram expressos em unidades de atividade por grama de poligalacturonase por minuto.

$\mathrm{O}$ experimento foi realizado em delineamento de blocos ao acaso, com quatro repetições, em que os tratamentos foram dispostos em arranjo fatorial $4 \mathrm{x} 4$, correspondente a quatro aplicações de substâncias húmicas $\left(0,20,40\right.$ e $\left.80 \mathrm{~L} \mathrm{ha}^{-1}\right)$ e quatro tipos de substratos orgânicos. Os resultados foram submetidos à análise de variância e à análise de regressão. Para realizar as análises estatísticas, foi utilizado o programa R (R Development Core Team, 2008).

\section{Resultados e Discussão}

A firmeza, a percentagem de solubilização das pectinas e as atividades das enzimas pectinametilesterase (PME) e poligalacturonase $(\mathrm{PG})$ em frutos do tomateiro híbrido 'Vênus' foram significativamente influenciadas pela interação entre as doses de substâncias húmicas e os substratos.

No substrato S1, observou-se aumento quadrático na firmeza, enquanto no substrato S3 observou-se redução quadrática, com o uso de doses crescentes das substâncias húmicas (Figura $1 \mathrm{~A}$ ). Incrementos nos valores médios da firmeza com a aplicação foliar de substâncias húmicas foram obtidos por Zaller (2006), em tomates 'Matina', e por Salman et al. (2005), em híbridos Sugar belle, de melancia.

Com relação à percentagem de solubilização das pectinas, houve redução nos percentuais médios pela aplicação de substâncias húmicas, quando as plantas foram cultivadas no S1 e S4 (Figura 1 B). Frutos obtidos de plantas cultivadas no S3 apresentaram declínio até a dose de 45,64 $\mathrm{L} \mathrm{ha}^{-1}$, seguido por uma ascensão dos valores. Para os frutos obtidos de plantas cultivadas no S2, houve aumento inicial dos valores médios de solubilização 
péctica, seguido de declínio. Obtiveram-se maiores valores médios da percentagem de solubilização $(51,32 \%)$ nos frutos obtidos de plantas cultivadas no $\mathrm{S} 2$ e com a aplicação de $40 \mathrm{~L} \mathrm{ha}^{-1}$. Os menores valores médios de percentagem de solubilização $(23,96 \%)$ foram obtidos nos frutos de plantas cultivadas no S4, com a aplicação de $40 \mathrm{~L} \mathrm{ha}^{-1}$.

O aumento no percentual de solubilização é geralmente correlacionado à diminuição da firmeza do tecido e, consequentemente, considerado parte importante do processso de maturação (Wakabayashi, 2000). No presente trabalho, os frutos obtidos de plantas cultivadas no substrato S1 apresentaram maior firmeza e menor solubilização, e aqueles cultivados no substrato S3 apresentaram menor firmeza e maior solubilização, com o uso de doses superiores a $60 \mathrm{~L} \mathrm{ha}^{-1}$ de substâncias húmicas (Figura 1 A e B).
No que se refere à atividade da enzima PME, os frutos obtidos de plantas cultivadas nos substratos S2 e S4 apresentaram redução com o uso de doses de substâncias húmicas superiores a 54,37 e 16,44 $\mathrm{L} \mathrm{ha}^{-1}$, respectivamente (Figura $1 \mathrm{C}$ ). Os obtidos de plantas cultivadas no S3 apresentaram ascensão de seus valores com a aplicação das substâncias húmicas com dosagens superiores a 24,47 L ha ${ }^{-1}$. Frutos obtidos de plantas cultivadas no S1 apresentaram redução da atividade enzimática com aplicação de doses de substâncias húmicas inferiores a 15,02 $\mathrm{L} \mathrm{ha}^{-1}$ e superiores a $61,24 \mathrm{~L} \mathrm{ha}^{-1}$.

Uma das possíveis causas da redução da atividade enzimática da PME pode estar relacionada ao aumento do conteúdo de açúcares totais pela aplicação crescente de substâncias húmicas (Pires, 2009), pois, de acordo com Jiang et al. (2003), substâncias como sacarose, maltose e glicose agem por meio de inibição não
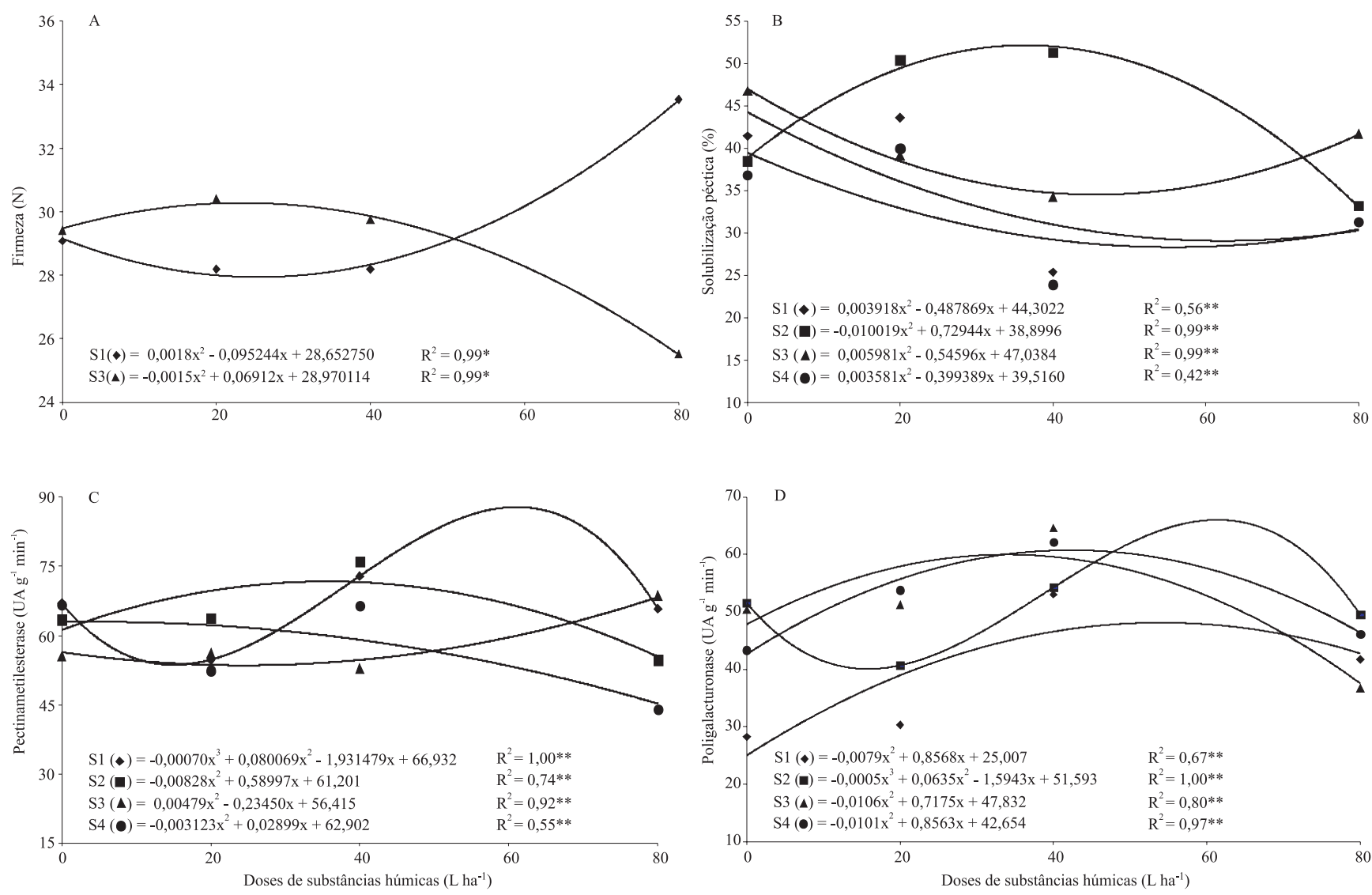

Figura 1. Efeitos da aplicação de doses crescentes de substâncias húmicas, em diferentes substratos, sobre: A, firmeza (N); B, percentagem de solubilização péctica; C e D, valores médios da atividade da pectinametilesterase e da poligalacturonase, respectivamente (em unidades de atividade por grama de enzima por minuto). S1, fibra de coco; S2, fibra de coco e casca de café carbonizada 1/3 (v/v); S3, fibra de coco e casca de café carbonizada 2/3 (v/v); e S4, casca de café carbonizada. 
competitiva nos sítios de ligação da PME. Conforme Vaughan et al. (1985), as substâncias húmicas atuam como estimulantes do crescimento vegetal, pela liberação de moléculas bioativas com ação semelhante à auxina, e ação direta em atividades enzimáticas em diversas rotas metabólicas. Entre as ações das auxinas, está a estimulação da produção de etileno (Salisbury, 1992). O aumento na produção de etileno leva à ativação da transcrição da enzima pectinemetilesterase (Watada, 1986), o que provavelmente justifica o aumento obtido na atividade enzimática, no presente estudo.

Obsevou-se ascensão da atividade enzimática da poligalacturonase dos frutos obtidos de plantas cultivadas nos substratos S1, S3 e S4, com o uso de doses de substâncias húmicas inferiores 59,65, 40,56 e 42,31 L ha-1, respectivamente (Figura $1 \mathrm{D}$ ). Frutos obtidos de plantas cultivadas no substrato S2 apresentaram redução da atividade enzimática, quando receberam doses de substâncias húmicas inferiores a 7,46 $\mathrm{L} \mathrm{ha}^{-1}$ e superiores a $68,75 \mathrm{~L} \mathrm{ha}^{-1}$.

Bicalho et al. (2000) sugeriram que a atividade da PME precede a atividade da PG, uma vez que a PME catalisa a desesterificação dos resíduos de galacturonosil, presentes no polímero homogalacturonano de ácido galacturônico, em que o grupo carboxílico se encontra metilesterificado e atua nos finais redutores e no interior das cadeias pécticas com alto grau de esterificação, reduzindo seu peso. A PG tem maior afinidade pelo substrato linear desmetilado, após a atuação da PME (Evangelista et al., 2000). Portanto, a redução na atividade da enzima poligalacturonase se deve, possivelmente, à menor atividade da enzima pectinametilesterase. Entretanto, para o maior entendimento do efeito dos substâncias húmicas e dos substratos orgânicos na ação da PG, são necessários mais estudos, pois esta enzima ocorre em uma variedade de isoenzimas, com tempos e substratos específicos de atuação.

\section{Conclusões}

1. Frutos obtidos de plantas cultivadas em substratos compostos por fibra de coco apresentam aumento na firmeza e redução da percentagem de solubilização péctica, com a aplicação de doses crescentes de substâncias húmicas.

2. O efeito das doses de substâncias húmicas sobre a firmeza, solubilidade de pectinas e atividade enzimática, em frutos de tomate, depende do substrato utilizado, e apresenta efeitos diferentes de acordo com a dose utilizada e a proporção de fibra de coco e casca de café presentes no substrato.

\section{Referências}

ALI, Z.M.; CHIN, L.H.; LAZAN, H. A comparative study on wall degrading enzymes, pectin modifications and softening during ripening of selected tropical fruits. Plant Science, v.167, p.317-327, 2004

ASSIS, S.A. de; FERREIRA, B.S.; FERNANDES, P.; TREVISAN, H.C.; CABRAL, J.M.S.; OLIVEIRA, O.M.M.F. Gelatin immobilized pectinmethylesterase for production of low methoxyl pectin. Food Chemistry, v.86, p.333-337, 2004.

BICALHO, U. de O.; CHITARRA, A.B.; CHITARRA, M.I.F.; COELHO, A.H.R. Modificações texturais em mamões submetidos à aplicação pós-colheita de cálcio e embalagem de PVC. Ciência e Agrotecnologia, v.24, p.136-146, 2000.

BITTER, T.; MUIR, H.M. A modified uronic acid carbazole reaction. Analytical Biochemistry, v.34, p.330-334, 1962.

BUESCHER, R.W.; FURMANSKI, R.J. Role of pectinesterase and polygalacturonase in the formation of woolliness in peaches. Journal of Food Science, v.43, p.264-266, 1978.

CASTEllane, P.D.; ARAÚJO, J.A.C. de. Cultivo sem solo: hidroponia. Jaboticabal: FUNEP, 1994. 43p.

DELFINE, S.; TOGNETTI, R.; DESIDERIO, E.; ALVINO, A. Effects of foliar application of $\mathrm{N}$ and humic acids on growth and yield of durum wheat. Agronomy for Sustainable Development, v.25, p.183-191, 2005.

DUENHAS, H.L. Cultivo orgânico de melão: aplicação de esterco e de biofertilizantes e substâncias húmicas via fertirrigação. 2004. 73p. Tese (Doutorado) - Escola Superior de Agricultura Luiz de Queiroz, Piracicaba.

EVANGELISTA, R.M.; CHITARRA, A.B.; CHITARRA, M.I.F. Influência da aplicação pré-colheita de cálcio na textura e na atividade das enzimas poligalacturonase, pectinametilesterase e $\beta$-galactosidase de mangas 'Tommy Atkins' armazenadas sob refrigeração. Ciência e Agrotecnologia, v.24, p.174-181, 2000.

FAÇANHA,A.R.; FAÇANHA,A.L.O.; OLIVARES, F.L.; GURIDI, F.; SANTOS, G. de A.;VELLOSO, A.C.X.; RUMJANEK, V.M.; BRASIL, F.; SCHRIPSEMA, J.; BRAZ-FILHO, R.; OLIVEIRA, M.A. de; CANELLAS, L.P. Bioatividade de ácidos húmicos: efeitos sobre o desenvolvimento radicular e sobre a bomba de prótons da membrana plasmática. Pesquisa Agropecuária Brasileira, v.37, p.1301-1310, 2002.

FERRARA, G.; BRUNETTI, G. Influence of foliar applications of humic acids on yield and fruit quality of Table grape cv. Itália. Journal International des Sciences de la Vigne et du Vin, v.42, p.79-87, 2008.

GUERRA, J.C.M.; SANTOS, G. de A.; SILVA, L.S. da; CAMARGO, F.A.O. Macromoléculas e substâncias húmicas. In: 
SANTOS, G. de A. (Ed.). Fundamentos da matéria orgânica do solo: ecossistemas tropicais e subtropicais. 2.ed. Porto Alegre: Metrópole, 2008. p.19-26.

JEN, J.J.; ROBINSON, M.L. Pectolytic enzymes in sweet bell peppers (Capsicum annuum L.). Journal of Food Science, v.49, p.1085-1087, 1984.

JIANG, C.M.; WU, M.C.; WU, C.L.; CHANG, H.M. Pectinesterase and polygalacturonase activities and textural properties of rubbery papaya (Carica papaya Linn.). Journal of Food Science, v.68, p.1590-1594, 2003.

KADER, A.A.; MORRIS, L.L.; STEVENS, M.A.; ALBUGHT-HOLTON, M. Composition and flavor quality of fresh market tomatoes as influenced by some post-harvest handling procedures. Journal of the American Society for Horticultural Science, v.103, p.6-13, 1978.

KALBITZ, K.; SOLINGER, S.; PARK, J.H.; MICHALZIK, B.; MATZNER, E. Controls on the dynamics of dissolved organic matter in soils: a review. Soil Science, v.165, p.277-304, 2000.

MCCREADY, R.M.; MCCOMB, E.A. Extraction and determination of total pectic materials in frutis. Analytical Chemistry, v.24, p.1986-1988, 1952.

NELSON, N. A photometric adaptation of the Somogyi method for the determination of glicose. The Journal of Biological Chemistry, v.153, p.375-380, 1944.

PICCOLO, A. The supramolecular structure of humic substances. Soil Science, v.166, p.810-832, 2001.

PIRES, C.R.F. Transformações químicas, físicas e bioquímicas de tomates submetidos à aplicação de ácidos húmicos e cultivados em diferentes substratos orgânicos. 2009. 85p. Dissertação (Mestrado) - Universidade Federal de Lavras, Lavras.

PIZZEGHELLO, D.; NICOLINI, G.; NARDI, S. Hormone-like activity of humic substances in Fagus sylvaticae forests. New Phytologist, v.151, p.647-657, 2001.

PRASANNA, V.; PRABHA, T.N.; THARANATHAN, R.N. Fruit ripening phenomena - an overview. Critical Reviews in Food Science and Nutrition, v.47, p.1-19, 2007.

PRESSEY, R.; AVANTS, J.K. Solubilization of cell walls by tomato polygalacturonases: effects of pectinesterases. Journal of Food Biochemistry, v.1, p.57-74, 1982.
R DEVELOPMENT CORE TEAM. R: A language and environment for statistical computing. Vienna: R Foundation for Statistical Computing, 2008. Disponível em: <http://www.R-project.org>. Acesso em: 15 dez. 2009.

RESENDE, J.M.; CHITARRA, M.I.; MALUF, W.R.; CHITARRA, A.B.; SAGGIN JUNIOR, O.J. Atividade de enzimas pectinametilesterase e poligalacturonase durante o amadurecimento de tomates do grupo multilocular. Horticultura Brasileira, v.22, p.206-201, 2004.

SALISBURY, F.B.; ROOS, C.W. Plant physiology. 4.ed. Belmont: Wadsworth, 1992. 682p.

SALMAN, S.R.; ABOU-HUSSEIN, S.D.; ABDEL-MAWGOUD, A.M.R.; EL-NEMR, M.A. Fruit yield and quality of watermelon as affected by hybrids and humic acid application. Journal of Applied Sciences Research, v.1, p.51-58, 2005.

TEJADA, M.; GONZALEZ, J.L. Effects of foliar application of a byproduct of the two-step olive oil mill process on rice yield. Europe Journal of Agronomy, v.21, p.31-40, 2004.

VAUGHAN, D.; MALCOLM, R.E.; ORD, B.G. Influence of humic substances on biochemical processes in plants. In: VAUGHAN, D.; MALCOLM, R.E. (Ed.). Soil organic matter and biological activity. Dordrecht: Kluwer Academic, 1985. p.77-108.

VAUGHAN, D.; ORD, B.G. An effect of soil organic matter on invertase activity in soil. Soil Biology and Biochemistry, v.12, p.449-450, 1980.

WAKABAYASHI, K. Changes in cell wall polysaccharides during fruit ripening. Journal of Plant Research, v.113, p.231-237, 2000.

WATADA, A.E. Effects of ethylene on the quality of fruits and vegetables. Food Technology, v.40, p.82-85, 1986.

YILDIRIM, E. Foliar and soil fertilization of humic acid affect productivity and quality of tomato. Acta Agriculturae Scandinavica, v.57, p.182-186, 2007.

ZALLER, J.G. Foliar spraying of vermicompost extracts: effects on fruit quality and indications of late-blight suppression of field-grown tomatoes. Biological Agriculture and Horticulture, v.24, p.165-180, 2006.

ZANDONADI, D.B.; CANELLAS, L.P.; FAÇANHA, A.R. Indolacetic and humic acids induce lateral root development through a concerted plasmalemma and tonoplast $\mathrm{H}^{+}$pumps activation. Planta, v.225, p.1583-1595, 2007.

Recebido em 3 de agosto de 2009 e aprovado em 29 de outubro de 2009 